\title{
Regulation of poly- $\gamma$-glutamic acid production in Bacillus subtilis GXA-28 by potassium
}

Wei Zeng ${ }^{\mathrm{abc}}$, Zhiqun Liang ${ }^{\mathrm{abc}}$, Zhi Li ${ }^{\mathrm{abc}}$, Yaxi Bian ${ }^{\mathrm{abc}}$, Zhihong $\mathrm{Li}^{\mathrm{abc}}$, Zhen Tang ${ }^{\mathrm{abc}}$, Guiguang Chen $^{\mathrm{abc}_{*}}$

${ }^{\text {a }}$ State Key Laboratory for Conservation and Utilization of Subtropical Agro-bioresources, Guangxi University, Nanning 530004, Guangxi, China

${ }^{\mathrm{b}}$ Key Laboratory of Ministry of Education for Microbial and Plant Genetic Engineering, Guangxi University, Nanning 530004, Guangxi, China

${ }^{c}$ College of Life Science and Technology, Guangxi University, Nanning 530004, Guangxi, China

*Correspondence author.

Guiguang Chen,

State Key Laboratory for Conservation and Utilization of Subtropical

Agro-bioresources, Key Laboratory of Ministry of Education for Microbial and Plant

Genetic Engineering, College of Life Science and Technology, Guangxi University,

100 Daxue Road, Nanning, Guangxi, China

Post code: 530004. Tel. / fax: +8607713271181.

E-mail address: chgg0313@163.com

Wei Zeng and Zhiqun Liang contributed equally to this work. 


\section{ABSTRACT}

It is a simple and effective method that controlling the production of fermented products by metal ions. In this study, effect of $\mathrm{KCl}$ on $\gamma$-PGA production by $B$. subtilis GXA-28 was investigated. $\mathrm{K}^{+}$was proved to be the true effector, and concentration of $201.2 \mathrm{mM}$ was optimized for $\gamma$-PGA production. Addition of $\mathrm{KCl}$ to medium effectively reduced broth viscosity from $4289.5 \mathrm{mPa} \cdot \mathrm{s}$ to $748.0 \mathrm{mPa} \cdot \mathrm{s}$ by $82.6 \%$ and increased $\gamma$-PGA yield from $18.36 \mathrm{~g} / \mathrm{L}$ to $25.62 \mathrm{~g} / \mathrm{L}$ by $39.5 \%$. Although high concentration $\mathrm{KCl}(>67.1 \mathrm{mM})$ suppressed cell growth, the maximum biomass with $201.2 \mathrm{mM}$ had been brought forward to $16 \mathrm{~h}$ and had a marked effect in prolonging cell viability. Metabolic flux and key enzyme activities analysis indicated that enhanced GDH, GOGAT and GLR are important for $\gamma$-PGA production. Specifically, the expression of $p g s \mathrm{~B}$ was improved 9.6-fold by $\mathrm{KCl}$ added, which might be another reason for enhanced $\gamma$-PGA production. In addition, that modulation of the D/L-glutamate ratio in $\gamma$-PGA and molecular weight could also be accomplished by variation of $\mathrm{KCl}$ concentrations. This work provided a simple control strategy for $\gamma$-PGA production, and it will be applied to $\gamma$-PGA production on a large scale in the future.

Keywords: Poly- $\gamma$-glutamic acid; Potassium; Bacillus subtilis; Yield; Viscosity 


\section{Introduction}

Poly- $\gamma$-glutamic acid, abbreviated as $\gamma$-PGA, is a promising biopolymer that polymerized via the $\alpha$-amino and $\gamma$-carboxylic groups of D- and L-glutamic acid residues. It has great value for development based on its excellent water-solubility and plasticity [1]. However, the diversity of yield, stereochemical composition, molecular weight and broth viscosity, which affected by variety of Bacillus species, environmental and nutritional conditions, have constrained its production and industrial application.

Currently, the $\gamma$-PGA yield is between 0 and $50 \mathrm{~g} / \mathrm{L}$ by batch fermentation in different strains, which is the most important factor to affect its industrial application [2]. Microbial produced $\gamma$-PGA can have molecular weights ranging from $100 \mathrm{kDa}$ to $10,000 \mathrm{kDa}$ and the ratio of L-isomer in stereochemical composition ranging from 0 to $100 \%[1,3]$, depending on strains and culture conditions. However, $\gamma$-PGA with different molecular weight and stereochemical composition has different applications. Besides, the viscosity of culture media increased with $\gamma$-PGA production, which may be the major factor liminting the increase of $\gamma$-PGA yield even using a high-producing strain. Therefore, how to control $\gamma$-PGA yield, stereochemical composition, molecular weight and broth viscosity is very important for the $\gamma$-PGA production. With the exception of screening specific strains, regulating medium component is an effective method.

Metallic ions as a component required of culture media, have been proved to play an important role in the cell growth, $\gamma$-PGA yield, stereochemical composition 
and molecular weight of $\gamma$-PGA producing strain. For example, $\gamma$-PGA yield was increased in the presence of $\mathrm{Ca}^{2+}$ in the B. subtilis CGMCC 2108 [4]. $\mathrm{Mn}^{2+}$ has an effect on prolonging the viability of cells which lead to the $\gamma$-PGA yield increased, and increasing the proportions of ${ }_{\mathrm{D}^{-}}$-isomers of $\gamma$-PGA in B. licheniformis $9945 \mathrm{~A}$ [5]. It was found that high concentration $\mathrm{Na}^{+}$could reduce the $\gamma$-PGA molecular weight in B. licheniformis WX-02 [6] and B. subtilis (chungkookjang) [7]. Besides, no $\gamma$-PGA was produced in the absence of $\mathrm{K}^{+}$or $\mathrm{Mg}^{2+}$ in the Bacillus sp. RKY3 [8]. The results of our previous studies showed that the $\mathrm{K}^{+}$phenomenon was also present in B. subtilis GXA-28. However, the relationships between $\mathrm{K}^{+}$and cell growth, $\gamma$-PGA yield, stereochemical composition, molecular weight and broth viscosity have not been investigated in $\gamma$-PGA producing strain.

In this study, we examined the effect of $\mathrm{K}^{+}$on $\gamma$-PGA production in detail, and evaluated this in scale-up fermentation by batch fermentation. Furthermore, the possible mechanisms of the $\mathrm{K}^{+}$regulation at the metabolic and transcriptional level were explored by metabolic flux analysis and RT-PCR method, respectively.

\section{Methods}

\subsection{Microorganism and medium}

B. subtilis GXA-28 (CCTCC M 2012347) was used as $\gamma$-PGA producer [9]. The seed medium contained glucose $10.0 \mathrm{~g} \cdot \mathrm{L}^{-1}$, yeast extract $5.0 \mathrm{~g} \cdot \mathrm{L}^{-1}$, L-glutamate 5.0 $\mathrm{g} \cdot \mathrm{L}^{-1}, \mathrm{KH}_{2} \mathrm{PO}_{4} 0.5 \mathrm{~g} \cdot \mathrm{L}^{-1}$, and $\mathrm{MgSO}_{4} \cdot 7 \mathrm{H}_{2} \mathrm{O} 0.1 \mathrm{~g} \cdot \mathrm{L}^{-1}$. In fermentation medium, glucose, yeast extract and L-glutamate were adjusted to 20.0, 2.5 and $20.0 \mathrm{~g} \cdot \mathrm{L}^{-1}$. Besides, $\mathrm{KCl}$ with concentration from 0 to $335 \mathrm{mM}\left(0\right.$ to $\left.25.0 \mathrm{~g} \cdot \mathrm{L}^{-1}\right)$ was added to the 
fermentation medium. Specially, adding $3.67 \mathrm{mM}\left(0.5 \mathrm{~g} \cdot \mathrm{L}^{-1}\right) \mathrm{KH}_{2} \mathrm{PO}_{4}$ to fermentation culture to ensure that $\gamma$-PGA was produced normally, and using it as the control group of $\mathrm{KCl}$ adding experiment. Initial $\mathrm{pH}$ was adjusted to $7.2 \pm 0.1$.

\subsection{Fermentation in shake flask and fermentor}

Fermentation in $250 \mathrm{~mL}$ flask and 3.6 L fermentor (INFORS HT, Switzerland) were performed as our previous study [10]. In brief, the GXA-28 cells were inoculated into $30 \mathrm{~mL}$ of seed medium in $250 \mathrm{~mL}$ flask and aerobically cultured at 45 ${ }^{\circ} \mathrm{C}$ for $12 \mathrm{~h}$ with shaking at $200 \mathrm{rpm}$. A $2 \%(\mathrm{v} / \mathrm{v})$ inoculums of seed culture were transferred to a $250 \mathrm{~mL}$ flask containing $50 \mathrm{~mL}$ fermentation medium, and cultured at $45{ }^{\circ} \mathrm{C}$ with $200 \mathrm{rpm}$. The batch fermentation was performed in a $3.6 \mathrm{~L}$ fermentor containing $2 \mathrm{~L}$ fermentation medium and $50 \mu \mathrm{L}$ antifoam (Sigma, USA) was added. The seed culture $(100 \mathrm{~mL})$ was inoculated to the medium to start the cultivation at 45 ${ }^{\circ} \mathrm{C}$. The $\mathrm{pH}$ was automatically controlled at $7.2 \pm 0.1$ by adding $2 \mathrm{~N} \mathrm{NaOH}$ and/or $2 \mathrm{~N}$ $\mathrm{HCl}$. The aeration rate was maintained at $1.2 \mathrm{vvm}$ and the agitation speed was gradually increased from $200 \mathrm{rpm}$ to $400 \mathrm{rpm}$ to increase dissolved oxygen.

\subsection{Metabolic flux and enzyme activity analysis}

The metabolic model for $\gamma$-PGA biosynthesis and stoichiometric representations in B. subtilis GXA-28 were established in our previous study [10]. The extracellular metabolites of glucose, glutamate, biomass, $\gamma$-PGA, $\mathrm{O}_{2}$, and $\mathrm{CO}_{2}$ were measured to calculate metabolic flux using Matlab 7.1. All the flux distributions were normalized by the glucose uptake rate on a basis of $100 \mathrm{mmol} \cdot \mathrm{g} \mathrm{DCW}^{-1} \cdot \mathrm{h}^{-1}$.

Cells grown in batch fermentation for $20 \mathrm{~h}$ were harvested by centrifugation, and 
prepared the cell extracts for isocitrate dehydrogenase (ICDH), glutamate

dehydrogenase (GDH), glutamate $\alpha$-oxoglutarate aminotransferase (GOGAT), $\alpha$-oxoglutarate dehydrogenase complex (ODHC), and glutamate racemase (GLR) assays [10-12]. Of which, enzyme activities of ICDH, GDH, GOGAT and ODHC were determined by appearance or disappearance of NADH or NADPH $(\varepsilon=6.22 /(\mathrm{mmol} / \mathrm{L}) / \mathrm{cm})$ at $340 \mathrm{~nm}$. One unit of activity was defined as the amount of enzyme catalyzing $1 \mu \mathrm{mol}$ of NADH or NADPH per min. GLR was analyzed by HPLC for D-glutamate, and one unit of activity was defined as the amount of enzyme catalyzing the formation of $1 \mu \mathrm{mol}$ of D-glutamate per min. Protein concentration was determined by Bradford method with bovine serum albumin as the standard [13].

\subsection{Real-time PCR}

RNA extraction and reverse transcriptase reaction were performed using the EZ-10 DNAaway RNA Mini Preps Kit (BBI, BS88133) and the RevertAid First Strand cDNA Synthesis Kit (Thermo Scientific, K1621), respectively. The relative quantitative real-time polymerase chain reaction (RT-PCR) was performed using 2xSG Fast qPCR Master Mix (SYBR Green) kit (BBI, B639271) on Roche Light Cycle 480. The pgsB (GeneBank: KP178960), one of the key gene of the $\gamma$-PGA synthase, is the target of analysis. 16s rDNA (GeneBank: JN815234) was selected as the endogenous reference gene. Primer pairs of these two genes were designed by the Primer Premier 5.0 software: $\mathrm{F}_{p g s \mathrm{~B}}\left(5^{\prime}\right.$-GAGCGAGCCTGGGCACT T-3') and $\mathrm{R}_{p g s \mathrm{~B}}$

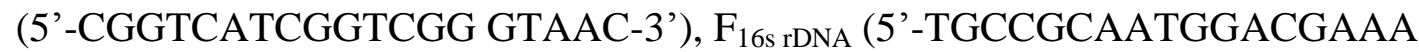

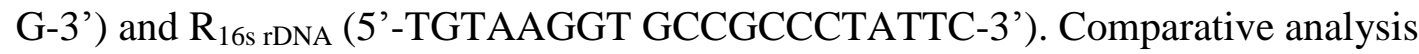


of $2^{-\Delta \Delta \mathrm{CT}}$ was used to calculate the fold change in gene expression relative to the initial control, which based on the amplification efficiency of the reference gene was consistent with the target gene[14].

\subsection{Analytical methods}

Dry cell weight (DCW) was determined by the method of Zeng et al. [10]. The viable cell was determined by the number of cfu per milliliter fermentation liquor (1 $\mathrm{cfu}=1$ colony forming unit) on the broth agar plate according to ten-fold dilution method. The $\gamma$-PGA yield was measured by UV or HPLC method [15]. The weight-average molecular weight $(\mathrm{Mw})$ and number-average molecular weight $(\mathrm{Mn})$ were determined by gel permeation chromatography (GPC) [9]. Viscosity of broth was measured by a viscometer (NDJ-8S, Jingtian, Shanghai, China). The ratio of D/L-glutamate in $\gamma$-PGA was determined by OPTA-derivatization method [11]. The concentration of glucose and L-glutamate were measured by a biosensor equipped with glucose and L-glutamic acid oxidase electrode (SBA-40D, Shandong Academy of Sciences, China).

\subsection{Statistical analyses}

Each experiment was carried out in triplicates, and three parallel experiments were performed for each experiment. One-way analysis of variance and the least significant difference (LSD) were used to interpret the difference in means at the $95 \%$ confidence level.

\section{Results and discussion}

3.1. Effects of $\mathrm{KCl}$ on cell viability and $\gamma$-PGA yield 
Figure 1 showed that the time course of cell viability and $\gamma$-PGA yield in medium containing various $\mathrm{KCl}$ concentrations. Generally, the yield that imporved by change of environmental conditions, to a large extyuent, had relation with higher cell viability. However, it is interesting that $\gamma$-PGA yield increased with $\mathrm{KCl}$ concentrations, but the cell viability decreased from $9.65 \times 10^{8} \mathrm{cfu} \cdot \mathrm{mL}^{-1}$ without $\mathrm{KCl}$ to $4.16 \times 10^{8} \mathrm{cfu} \cdot \mathrm{mL}^{-1}$ with $335.3 \mathrm{mM}\left(25 \mathrm{~g} \cdot \mathrm{L}^{-1}\right) \mathrm{KCl}$. To the best of our knowledge, low concentration of $\mathrm{K}^{+}$had a protective effect enabling cells to survive during osmotic stress [16], but $\mathrm{K}^{+}$had an analogous osmotic stress toxic as $\mathrm{Na}^{+}$when it present excessively [17]. In addition, the maximum yield of $\gamma$-PGA was obtained at $22 \mathrm{~h}$ regardless of $\mathrm{KCl}$ concentrations. The yield was $22.57 \pm 0.86 \mathrm{~g} \cdot \mathrm{L}^{-1}$ with productivity $1.03 \mathrm{~g} \cdot \mathrm{L}^{-1} \cdot \mathrm{h}^{-1}$ and apparent conversion rate $113 \%$ as $201.2 \mathrm{mM} \mathrm{KCl}$ added, which was 1.36-fold higher than that without $\mathrm{KCl}$ added. Although high concentration $\mathrm{KCl}(>67.1 \mathrm{mM})$ suppressed cell growth, the maximum viable count with $201.2 \mathrm{mM}$ had been brought forward to $16 \mathrm{~h}$ and had a marked effect in prolonging cell viability. This may be one of the reasons for improving $\gamma$-PGA yield. A similar phenomenon also appeared in B. licheniformis ATCC $9945 \mathrm{~A}, \mathrm{Mn}^{2+}$ has effective in prolonging the viability of cells which lead to the $\gamma$-PGA yield increased [5].

$\mathrm{K}^{+}$and $\mathrm{Cl}^{-}$coexist in culture medium when $\mathrm{KCl}$ was added, and which of these two ions is truly responsible for $\gamma$-PGA production. To investigate this, $\mathrm{KH}_{2} \mathrm{PO}_{4}$ and $\mathrm{NaCl}$ were selected to replace $\mathrm{KCl}$ at $201.2 \mathrm{mM}$. There are similar effects on $\gamma$-PGA production by $\mathrm{KH}_{2} \mathrm{PO}_{4}$, but no obvious regulating effects on $\gamma$-PGA production by 
$\mathrm{NaCl}$ (data not shown). Based on above results, $\mathrm{K}^{+}$was proved to be the true effector, and has a certain regulation effect on $\gamma$-PGA yield.

3.2. Glucose and glutamate utilization

B. subtilis GXA-28 can be produced $\gamma$-PGA under relatively simple nutritional components, of which glucose was chosen as a preferred carbon source and L-glutamate was required as substrate. Then, the residual glucose and glutamate as a function of both $\mathrm{KCl}$ concentration and culture time were measured (Fig. 2). The glucose utilization increased as the culture medium containing low concentration $\mathrm{K}^{+}$ $(\leq 67.1 \mathrm{mM})$, which was consistent with the observation of high cell viability. It was interesting that the residual glutamate all remained about $7 \mathrm{~g} / \mathrm{L}$ at the end of fermentation, which may be considered as "background level of substrate" (Table 1). However, the total amount of glutamate including glutamate unit in $\gamma$-PGA and residual glutamate in broth was much more than the added glutamate, and increased with the $\mathrm{KCl}$ concentration. It was deduced that the substrate of $\gamma$-PGA came from two parts: one is from extracellular glutamate which exists in the medium by artificial added, and others derived from intracellular glutamate which obtained via glycolysis and the tricarboxylic acid cycle by glucose. Based on above results, it was speculated that glucose was mainly used to cell grow and little was used to participate in $\gamma$-PGA synthesis when the culture containing low concentration $\mathrm{KCl}$, but more glucose was involved in $\gamma$-PGA synthesis when the concentration of $\mathrm{KCl}$ increased. Therefore, addition of $\mathrm{KCl}$ can be used as a control strategy to improve $\gamma$-PGA yield by enhancing the conversion rate of carbon source. 
As shown in Table 1, one-way analysis of variance by F-test was used to interpret the difference in results of five group for $\gamma$-PGA production. Results showed that all parameter obtained from $\gamma$-PGA production were significant, including cell viability, $\gamma$-PGA yield, residual glucose, residual L-glutamate, total L-glutamate, productivity, and apparent conversion rate. The maxmium yield and apparent conversion rate were obtained at $201.2 \mathrm{mM} \mathrm{KCl}$, whether or not it was significant compared with other experimental group. Thus, comparative analysis of the difference between the $201.2 \mathrm{mM} \mathrm{KCl}$ group and other concentrations $\mathrm{KCl}$ group by the least significant difference method (LSD) was carried out (Table 2). Compared with 0, 13.4 and $67.1 \mathrm{mM} \mathrm{KCl}$ group, all parameter obtained from $201.2 \mathrm{mM} \mathrm{KCl}$ group were significant, except total L-glutamate with $67.1 \mathrm{mM} \mathrm{KCl}$ group. However, compared with $335.3 \mathrm{mM} \mathrm{KCl}$ group, many parameter were not significant, including $\gamma$-PGA yield, residual L-glutamate, total L-glutamate, productivity, and apparent conversion rate. These results indicated that it was not obvious promoting effect on $\gamma$-PGA production by addition of $\mathrm{KCl}$ unceasingly as more than $201.2 \mathrm{mM}$.

\subsection{Molecular weight and stereochemical composition of $\gamma$-PGA regulated by $\mathrm{KCl}$}

It was known that $\gamma$-PGA with different molecular weight and stereochemical composition have different applications. For example, $\gamma$-PGA with low enough molecular weight and high content of D-glutamate was preferred used for medical applications because it provide the proper sustained release profile during biodegradation [18]. But, $\gamma$-PGA with high molecular weight $\gamma$-PGA (over $2.0 \times 10^{6}$ $\mathrm{g} \cdot \mathrm{mol}^{-1}$ ) and high content of L-glutamate was generally used as a viscosity-adding 
agent or an immunological enhancement effect on mammals due to its excellent bio-compatibility [19]. Therefore, looking for some simple strategies for controlling the $\gamma$-PGA molecular weight and stereochemical composition is valuable to meet the needs of different applications.

As shown in Table 3, the weight-average molecular weight (Mw) and number-average molecular weight $(\mathrm{Mn})$ increased respectively from $3.05 \times 10^{6}$ $\mathrm{g} \cdot \mathrm{mol}^{-1}$ to $4.95 \times 10^{6} \mathrm{~g} \cdot \mathrm{mol}^{-1}$ by $62.3 \%$ and $1.52 \times 10^{6} \mathrm{~g} \cdot \mathrm{mol}^{-1}$ to $2.95 \times 10^{6} \mathrm{~g} \cdot \mathrm{mol}^{-1}$ by $94.1 \%$, and the polydispersity still remained relatively stable, when $\mathrm{KCl}$ added from 0 to $335.3 \mathrm{mM}$. The result differs from other metal ions. For example, there were no readily interpretable correlations between $\mathrm{Mn}^{2+}$ and $\gamma$-PGA molecular weight in B. licheniformis ATCC9945A [5], while high concentration of $\mathrm{Na}^{+}$could reduce $\gamma$-PGA molecular weight in B. licheniformis WX-02 [6] and $\mathrm{Ca}^{2+}$ have no effect on $\gamma$-PGA molecular weight in B. subtilis CGMCC2108 [4]. These diversities may be due to the differences of strain properties and $\gamma$-PGA synthetase system, which need to be further investigated.

That modulation of the D/L-glutamate ratio in $\gamma$-PGA can also be accomplished by variation of $\mathrm{KCl}$ concentration (Table 2). The percentage L-glutamate content decreased by approximately $12 \%$ with $\mathrm{KCl}$ added to $335.3 \mathrm{mM}$, which showed a similar effect with $\mathrm{Mn}^{2+}$ in B. licheniformis ATCC9945A [5]. Above results showed that $\mathrm{KCl}$ has a significant regulating effect on the molecular weight and stereochemical composition of $\gamma$-PGA, so it is very likely to develop into a simple control strategy for industrial production. 


\subsection{Control of fermentation broth viscosity}

The culture medium for $\gamma$-PGA production becomes highly viscous as the $\gamma$-PGA concentration increased and exhibits non-Newtonian rheology, which limits dissolved oxygen and mass transfer, then inhibits cell growth and $\gamma$-PGA production. Thus, the viscosity of the fermentation broth is one of the most important influencing factors in $\gamma$-PGA production. As shown in Fig. 3, it's significantly that the viscosity of broth decreased sharply with the increase of $\mathrm{KCl}$ concentrations. The maximum viscosity in $335.3 \mathrm{mM} \mathrm{KCl}$ was $521.1 \pm 28.5 \mathrm{mPa} \cdot \mathrm{s}$, which reduced by $85.4 \%$ than that of without $\mathrm{KCl}$ added. Moreover, the viscosity of culture medium in 201.2 and $335.3 \mathrm{mM} \mathrm{KCl}$ were at a relatively low level during the whole fermentation process. To the best of our knowledge, there was no report about that the viscosity of $\gamma$-PGA broth was significantly decreased by $\mathrm{KCl}$. Why does $\mathrm{KCl}$ affect the viscosity of $\gamma$-PGA solution so much? It presumed that this phenomenon was due to the change of $\gamma$-PGA conformation caused by $\mathrm{KCl}$. Previous studies from He et al. showed that the $\gamma$-PGA was in a helical conformation at low ionic strength, while changed to a mixture of helix and $\beta$-sheet at $0.1 \mathrm{M}$, and adopted predominantly $\beta$-sheet at $0.5 \mathrm{M}$ [20]. These results indicated that $\mathrm{KCl}$ can be used to control the viscosity of $\gamma$-PGA fermentation broth, thereby improving $\gamma$-PGA production.

3.5. Characterization of $\gamma$-PGA production with $\mathrm{KCl}$ addition in fermentor by batch fermentation

Shake flask experiment results showed that high concentration $\mathrm{KCl}$ had obvious effects on $\gamma$-PGA production. To evaluate this in scale-up fermentation, the time 
courses of $\gamma$-PGA yield, cell growth, broth viscosity, glucose and glutamate consumption in 3.6-L fermentor without (Fig. 4A) or with (Fig. 4B) $\mathrm{KCl}$ were investigated. Results showed that $\gamma$-PGA production in fermentor was consistent with in shake flask. The maximum yield of $\gamma$-PGA was obtained at $22 \mathrm{~h}$ regardless of A or $\mathrm{B}$, but the yield in B was $25.62 \pm 0.95 \mathrm{~g} \cdot \mathrm{L}^{-1}$ with productivity $1.16 \mathrm{~g} \cdot \mathrm{L}^{-1} \cdot \mathrm{h}^{-1}$, which was 1.4-fold higher than that in A. Although the viable count decreased after adding $\mathrm{KCl}$, the maximum growth in $\mathrm{B}$ had been brought forward to $16 \mathrm{~h}$ and had a marked effect in prolonging cell viability. However, it's interesting that the glucose in A was consuming much faster than in B, but the residual glutamate all remained about 6 $g \cdot L^{-1}$ at the end of fermentation. The viscosity of broth decreased sharply from 4289.5 $\pm 198.0 \mathrm{mPa} \cdot \mathrm{s}$ in A to $748.0 \pm 32.0 \mathrm{mPa} \cdot \mathrm{s}$ in $\mathrm{B}$ by $82.6 \%$. These results indicated that $\mathrm{KCl}$ concentration was one key influencing factor for $\gamma$-PGA production in B. subtilis. Thus, adding $\mathrm{KCl}$ can be used as an effective strategy to control $\gamma$-PGA fermentation.

\subsection{Analysis of $\mathrm{KCl}$ regulation by metabolic analysis and RT-PCR}

In order to investigate the possible mechanisms of $\mathrm{KCl}$ regulation at the metabolic and transcriptional level, the metabolic flux and enzyme activities of key metabolic branch without (Fig. 5A) or with (Fig. 5B) KCl were measured. Furthermore, the gene of $\operatorname{pgs}_{s} \mathrm{~B}$ that responsible for catalyzing the $\gamma$-PGA synthesis in $\gamma$-PGA synthetase complex was also assayed.

As shown in Fig. 5, the carbon flux from iso-citrate to $\alpha$-oxoglutarate increased and from $\alpha$-oxoglutarate to succinyl-CoA decreased with $\mathrm{KCl}$ added. Thus, the carbon flux from $\alpha$-oxoglutarate to glutamate reached $19.2 \mathrm{mmol} \cdot \mathrm{g} \mathrm{DCW}^{-1} \cdot \mathrm{h}^{-1}$ when $\mathrm{KCl}$ 
added, which was 3.84-fold higher than that of without $\mathrm{KCl}$. The changes of enzyme activity of ICDH, ODHC, GDH and GOGAT were consistent with the flux distribution. Generally, GDH and GOGAT are responsible for the shunt from $\alpha$-oxoglutarate to glutamate in many bacteria [12]. In this case, the activity of GOGAT was $4.9 \times 10^{-2} \mathrm{U} \cdot \mathrm{mg}^{-1}$ when $\mathrm{KCl}$ added, which was 2.88 -fold higher than that of without $\mathrm{KCl}$. However, the activity of GDH was improved 2.13-fold by $\mathrm{KCl}$ added. The result showed that the contribution of GOGAT to the conversion of $\alpha$-oxoglutarate to glutamate was slightly more than that of the GDH. Furthermore, the extracellular glutamate uptake rate between A and B are not significantly different. Therefore, the higher yield of $\gamma$-PGA reached $25.62 \mathrm{~g} \cdot \mathrm{L}^{-1}$ with $\mathrm{KCl}$ added, which mainly resulted from the increase of intracellular glutamate. In addition, transcriptional analysis showed that the expression of $p g s \mathrm{~B}$ was improved 9.6-fold by $\mathrm{KCl}$ added, which might be another reason for the improved $\gamma$-PGA production.

Previous reported that the conversion of L-glutamate to D-isomer in B. subtilis was mainly mediated by glutamate racemase [21]. Thus, in order to investigate the possible explanation for the observed stereochemical modulation by $\mathrm{KCl}$ in $B$. subtilis GXA-28, the metabolic flux and enzyme activities of glutamate node were analyzed. Results showed that the flux from L-glutamate to D-isomer increased from 22.9 to $37.6 \mathrm{mmol} \cdot \mathrm{g} \mathrm{DCW}^{-1} \cdot \mathrm{h}^{-1}$ and the activities of GLR increased from 0.42 to $0.53 \mathrm{U} \cdot \mathrm{mg}^{-1}$ when $\mathrm{KCl}$ added. Thereby, the carbon flux from D-glutamate to $\gamma$-PGA reached 35.2 mmol.g DCW ${ }^{-1} \cdot \mathrm{h}^{-1}$, which was increased $78.7 \%$ that that of without $\mathrm{KCl}$. These results indicated that GLR plays an important role during the process of $\gamma$-PGA 
stereochemical regulation by $\mathrm{KCl}$.

\section{Conclusions}

The present study investigated the effect of $\mathrm{KCl}$ on $\gamma$-PGA production in detail by B. subtilis GXA-28. Results showed that addition of $\mathrm{KCl}$ could significantly increase the yield and molecular weight and reduce the broth viscosity. The $\gamma$-PGA stereochemical composition also can be regulated by $\mathrm{KCl}$. Furthermore, the effect of $\mathrm{KCl}$ regulation was verified in the fermentor. The yield improvement and stereochemical modulation might be due to the changes of metabolic flux and enzyme activities around key metabolic branch. This work provided a simple control strategy for $\gamma$-PGA production, and it will be applied to $\gamma$-PGA production on a large scale in the future.

\section{Acknowledgments}

This work was financially supported by the General Research Project of Institutions of Higher Learning of Guangxi (KY2015YB001), the Innovation Project of Guangxi Graduate Education (YCSZ2015042), the National Science Foundation of China (21506039, 31560448), the Research Project of State Key Laboratory for Conservation and Utilization of Subtropical Agro-bioresources, the Director's Fund of Key Laboratory of Ministry of Education for Microbial and Plant Genetic Engineering.

\section{References}

[1] Shih IL, Van YT. The production of poly-( $\gamma$-glutamic acid) from microorganisms and its various applications. Bioresour Technol 2001;79:207-25. 
[2] Bajaj I, Singhal R. Poly (glutamic acid) - An emerging biopolymer of commercial interest. Bioresour Technol 2011;102:5551-61.

[3] Ogunleye A, Bhat A, Irorere VU, Hill D, Williams C, Radecka I. Poly-gamma-glutamic acid: production, properties and applications. Microbiology 2015;161:1-17.

[4] Huang B, Qin P, Xu Z, Zhu R, Meng Y. Effects of $\mathrm{CaCl}_{2}$ on viscosity of culture broth, and on activities of enzymes around the 2-oxoglutarate branch, in Bacillus subtilis CGMCC 2108 producing poly-( $\gamma$-glutamic acid). Bioresour Technol 2011;102:3595-8.

[5] Cromwick AM, Gross RA. Effects of manganese (II) on Bacillus licheniformis ATCC 9945A physiology and $\gamma$-poly(glutamic acid) formation. Int $\mathrm{J}$ Biol Macromol 1995;17:259-67.

[6] Wei X, Ji Z, Chen S. Isolation of halotolerant Bacillus licheniformis WX-02 and regulatory effects of sodium chloride on yield and molecular sizes of poly- $\gamma$-glutamic acid. Appl Biochem Biotechnol 2010;160:1332-40.

[7] Ashiuchi M, Kamei T, Baek DH, Shin SY, Sung MH, Soda K, Yagi T, Misono H. Isolation of Bacillus subtilis (chungkookjang), a poly- $\gamma$-glutamate producer with high genetic competence. Appl Microbiol Biotechnol 2001;57:764-9.

[8] Jung DY, Jung S, Yun JS, Kim JN, Wee YJ, Jang HG, Ryu HW. Influences of cultural medium component on the production of $\operatorname{poly}(\gamma$-glutamic acid $)$ by Bacillus sp. RKY3. Biotechnology and Bioprocess Engineering 2005;10:289-95.

[9] Zeng W, Lin Y, Qi Z, He Y, Wang D, Chen G, Liang Z. An integrated 
high-throughput strategy for rapid screening of poly( $\gamma$-glutamic acid)-producing bacteria. Appl Microbiol Biotechnol 2013;97:2163-72.

[10] Zeng W, Chen G, Wang Q, Zheng S, Shu L, Liang Z. Metabolic studies of temperature control strategy on poly $(\gamma$-glutamic acid $)$ production in a thermophilic strain Bacillus subtilis GXA-28. Bioresour Technol 2014;155:104-10.

[11] Jiang F, Qi G, Ji Z, Zhang S, Liu J, Ma X, Chen S. Expression of glr gene encoding glutamate racemase in Bacillus licheniformis WX-02 and its regulatory effects on synthesis of poly- $\gamma$-glutamic acid. Biotechnol Lett 2011;33:1837-40.

[12] Meers JL, Tempest DW, Brown CM. 'Glutamine(amide):2-oxoglutarate amino transferase oxido-reductase (NADP); an enzyme involved in the synthesis of glutamate by some bacteria. J Gen Microbiol 1970;64:187-94.

[13] Bradford MM. A rapid and sensitive method for the quantitation of microgram quantities of protein utilizing the principle of protein-dye binding. Anal Biochem 1976;72:248-54.

[14] Livak KJ, Schmittgen TD. Analysis of relative gene expression data using real-time quantitative PCR and the 2(-Delta Delta $\mathrm{C}(\mathrm{T})$ ) Method. Methods 2001;25:402-8.

[15] Zeng W, Chen G, Zhang Y, Wu K, Liang Z. Studies on the UV spectrum of poly $(\gamma$-glutamic acid) based on development of a simple quantitative method. Int J Biol Macromol 2012;51:83-90.

[16] Gauthier MJ, Flatau GN, Le Rudulier D, Clement RL, Combarro Combarro MP. 
Intracellular accumulation of potassium and glutamate specifically enhances survival of Escherichia coli in seawater. Appl Environ Microbiol 1991;57:272-6.

[17] Botsford JL, Alvarez M, Hernandez R, Nichols R. Accumulation of glutamate by Salmonella typhimurium in response to osmotic stress. Appl Environ Microbiol 1994;60:2568-74.

[18] Li C, Yu DF, Newman RA, Cabral F, Stephens LC, Hunter N, Milas L, Wallace S. Complete regression of well-established tumors using a novel water-soluble poly(L-glutamic acid)-paclitaxel conjugate. Cancer Res 1998;58:2404-9.

[19] Poo H, Park C, Kwak MS, Choi DY, Hong SP, Lee IH, Lim YT, Choi YK, Bae SR, Uyama H, Kim CJ, Sung MH. New biological functions and applications of high-molecular-mass poly- $\gamma$-glutamic acid. Chem Biodivers 2010;7:1555-62.

[20] He LM, Neu MP, Vanderberg LA. Bacillus lichenformis gamma-glutamyl exopolymer: Physicochemical characterization and U(VI) interaction. Environ Sci Technol 2000;34:1694-701.

[21] Ashiuchi M, Tani K, Soda K, Misono H. Properties of glutamate racemase from Bacillus subtilis IFO 3336 producing poly- $\gamma$-glutamate. J Biochem $1998 ; 123: 1156-63$.

[22] Xu H, Jiang M, Li H, Lu D, Ouyang P. Efficient production of poly $(\gamma$-glutamic acid) by newly isolated Bacillus subtilis NX-2. Process Biochem 2005;40:519-23. 


\section{Figure legends}

Figure 1 Time course of cell viability (A) and $\gamma$-PGA yield (B) in medium containing various $\mathrm{KCl}$ concentrations by $B$. subtilis $\mathrm{GXA}-28 . \mathrm{KCl}: 0 \mathrm{mM}(\square) ; 13.4 \mathrm{mM}(\boldsymbol{\Delta})$; $67.1 \mathrm{mM}(\diamond) ; 201.2 \mathrm{mM}(\bullet) ; 335.3 \mathrm{mM}(\lesssim)$.

Figure 2 Time course of the utilization of glucose (A) and L-glutamate (B) in medium containing various $\mathrm{KCl}$ concentrations by $B$. subtilis $\mathrm{GXA}-28 . \mathrm{KCl}$ : $0 \mathrm{mM}$ (); $13.4 \mathrm{mM}(\boldsymbol{\Delta}) ; 67.1 \mathrm{mM}(\diamond) ; 201.2 \mathrm{mM}(\bullet) ; 335.3 \mathrm{mM}(\succsim)$.

Figure 3 Time course of fermentation broth viscosity with various $\mathrm{KCl}$ concentrations by B. subtilis GXA-28. KCl: $0 \mathrm{mM}(\square) ; 13.4 \mathrm{mM}(\boldsymbol{\Delta}) ; 67.1 \mathrm{mM}(\diamond)$; $201.2 \mathrm{mM}(\bullet) ; 335.3 \mathrm{mM}(\hat{\jmath})$.

Figure 4 Time courses of $\gamma$-PGA production in 3.6-L fermentor by batch fermentation. A: control; B: addition of $201.2 \mathrm{mM} \mathrm{KCl}$. Error bars are given showing standard deviations for $\mathrm{n}=3$.

Figure 5 Carbon flux distribution and enzymes activities at $\alpha$-oxoglutarate, glutamate racemization and $\gamma$-PGA synthesis branch point in $B$. subtilis GXA-28 without (A) or with (B) $\mathrm{KCl}$. The metabolic fluxes were given in units of $\mathrm{mmol} \cdot \mathrm{g} \mathrm{DCW}{ }^{-1} \cdot \mathrm{h}^{-1}$. The unit of enzyme activity was $\mathrm{U} \cdot \mathrm{mg}^{-1}$ protein. Abbreviations: ICDH, isocitrate dehydrogenase; ODHC, $\alpha$-ketoglutarate dehydrogenase; GDH, glutamate dehydrogenase; GOGAT, glutamate $\alpha$-oxoglutarate aminotransferase; GLR, glutamate racemase; iso-CIT, isocitric acid; $\alpha \mathrm{KG}, \alpha$-ketoglutarate; SUC-CoA, succinyl coenzyme A; in-[L]-GLU, intracellular L-glutamic acid; ex-[L]-GLU, extracellular L-glutamic acid; in-[D]-GLU, intracellular D-glutamic acid. 
Table 1 Effect of $\mathrm{KCl}$ on the $\gamma$-PGA production and one-way analysis of variance.

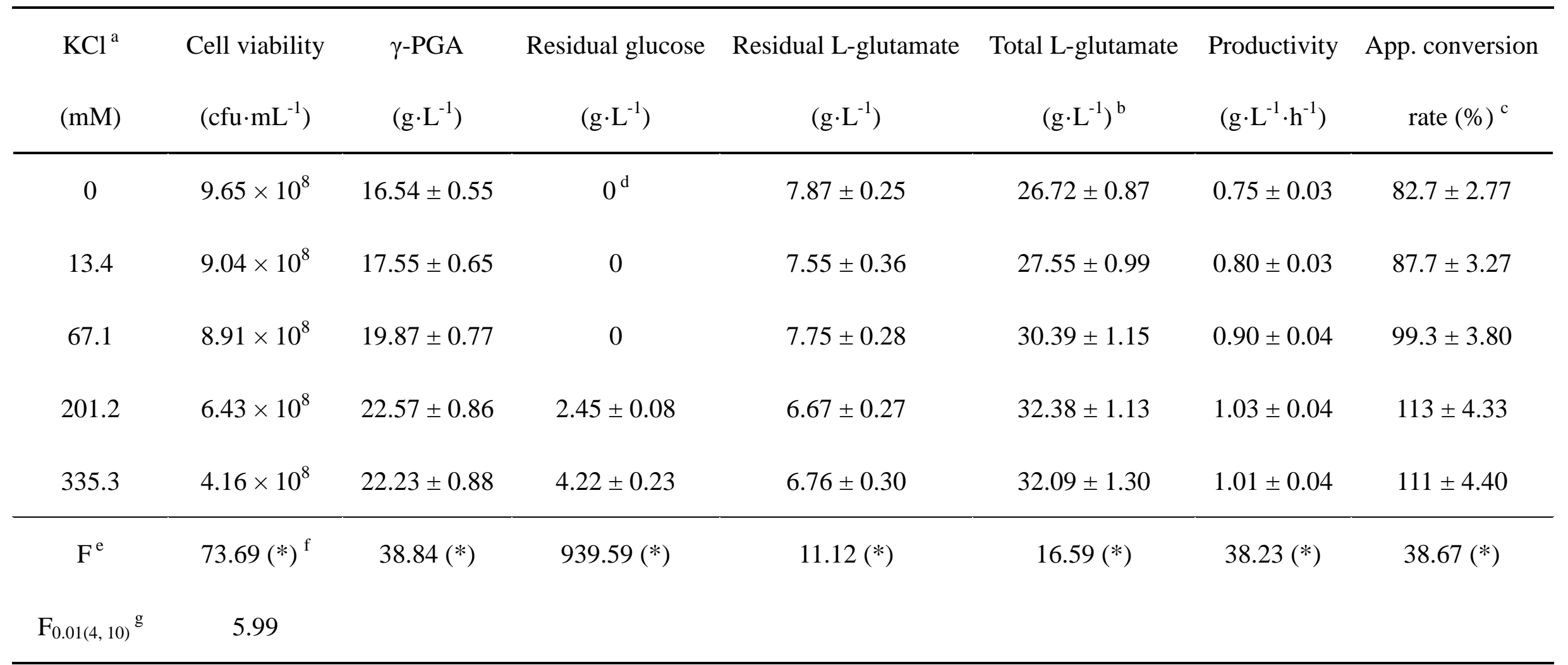

${ }^{\text {a }}$ Fermentation was carried out in $250 \mathrm{~mL}$ flask at $45{ }^{\circ} \mathrm{C}$ and $200 \mathrm{rpm}$ with various $\mathrm{KCl}$ concentrations. The other components of the culture were the same, including glucose $20.0 \mathrm{~g} / \mathrm{L}$, yeast extract $2.5 \mathrm{~g} / \mathrm{L}$, L-glutamate $20.0 \mathrm{~g} / \mathrm{L}, \mathrm{KH}_{2} \mathrm{PO}_{4} 0.5 \mathrm{~g} / \mathrm{L}$, and $\mathrm{MgSO}_{4} \cdot 7 \mathrm{H}_{2} \mathrm{O} 0.1 \mathrm{~g} / \mathrm{L}$. 
${ }^{\mathrm{b}}$ Total amount of L-glutamate was amount of $\gamma$-PGA $\times 147 / 129$ plus residual L-glutamate in the culture broth, 147/129 was coefficient [22].

${ }^{c}$ Apparent conversion rate was defined as the ratio of $\gamma$-PGA to the amount of L-glutamate added to the medium.

${ }^{\mathrm{d}}$ Can not be detected by SBA-40D biosensor.

${ }^{\mathrm{e}}$ One-way analysis of variance by F-test.

${ }^{\mathrm{f}}$ The difference in results of five group was significant if the numerical value was greater than $\mathrm{F}_{0.01(4,10)}$, and marked with an asterisk.

${ }^{\mathrm{g}}$ Obtained by F-value table. 
Table 2 Comparative analysis of the difference between the $201.2 \mathrm{mM} \mathrm{KCl}$ group and other concentrations $\mathrm{KCl}$ group by the least significant difference method (LSD).

\begin{tabular}{|c|c|c|c|c|c|c|c|}
\hline $\mathrm{KCl}$ & Cell viability & $\gamma$-PGA & Residual glucose & Residual L-glutamate & Total L-glutamate & Productivity & App. conversion \\
\hline$(\mathrm{mM})$ & $\left(\mathrm{cfu} \cdot \mathrm{mL}^{-1}\right)$ & $\left(g \cdot L^{-1}\right)$ & $\left(\mathrm{g} \cdot \mathrm{L}^{-1}\right)$ & $\left(g \cdot L^{-1}\right)$ & $\left(\mathrm{g} \cdot \mathrm{L}^{-1}\right)$ & $\left(\mathrm{g} \cdot \mathrm{L}^{-1} \cdot \mathrm{h}^{-1}\right)$ & rate $(\%)$ \\
\hline 0 & $0.76(*)^{\mathrm{a}}$ & $6.03(*)$ & $2.45(*)$ & $1.2(*)$ & $5.66(*)$ & $0.28(*)$ & $30.17(*)$ \\
\hline 13.4 & $0.62(*)$ & $5.02(*)$ & $2.45(*)$ & $0.89(*)$ & $4.83(*)$ & $0.23(*)$ & $25.13(*)$ \\
\hline 67.1 & $0.56(*)$ & $2.7(*)$ & $2.45(*)$ & $1.08(*)$ & 1.99 & $0.13(*)$ & $13.53(*)$ \\
\hline 335.3 & $0.53(*)$ & $0.34(\mathrm{NS})^{\mathrm{b}}$ & $1.78(*)$ & 0.09 (NS) & $0.29(\mathrm{NS})$ & $0.02(\mathrm{NS})$ & $1.73(\mathrm{NS})$ \\
\hline $\operatorname{LSD}_{0.01}{ }^{\mathrm{b}}$ & 0.28 & 1.95 & 0.28 & 0.76 & 2.85 & 0.09 & 9.75 \\
\hline
\end{tabular}

${ }^{\mathrm{a}}$ The numerical value represents that the value difference between the $201.2 \mathrm{mM} \mathrm{KCl}$ group and other concentrations $\mathrm{KCl}$ group. The difference was significant if the numerical value was greater than $\operatorname{LSD}_{0.01}$, and marked with an asterisk.

${ }^{\mathrm{b}} \mathrm{NS}$ represent not significant. 
Table 3 Effect of $\mathrm{KCl}$ on the molecular weight and stereochemical composition of $\gamma$-PGA.

\begin{tabular}{ccccc}
\hline $\mathrm{KCl}$ & $\mathrm{Mw}$ & $\mathrm{Mn}$ & Polydispersity & L-Isomer $(\%)$ \\
$(\mathrm{mM})$ & $\left(\times 10^{6} \mathrm{~g} \cdot \mathrm{mol}^{-1}\right)$ & $\left(\times 10^{6} \mathrm{~g} \cdot \mathrm{mol}^{-1}\right)$ & & \\
\hline 0 & $3.05 \pm 0.29$ & $1.52 \pm 0.15$ & 2.01 & $30.52 \pm 1.18$ \\
13.4 & $3.72 \pm 0.35$ & $1.78 \pm 0.19$ & 2.09 & $27 \pm 1.12$ \\
67.1 & $3.95 \pm 0.38$ & $1.96 \pm 0.22$ & 2.02 & $24.31 \pm 0.95$ \\
201.2 & $4.92 \pm 0.37$ & $2.57 \pm 0.23$ & 1.91 & $19.63 \pm 0.89$ \\
335.3 & $4.95 \pm 0.43$ & $2.95 \pm 0.26$ & 1.68 & $18.79 \pm 0.81$ \\
\hline $\mathrm{F}^{\mathrm{a}}$ & $14.91(*)^{\mathrm{b}}$ & $22.87(*)$ & $1.10(\mathrm{NS})^{\mathrm{c}}$ & $73.78(*)$ \\
$\mathrm{F}_{0.01(4,10)}{ }^{\mathrm{d}}$ & 5.99 & & & \\
\hline
\end{tabular}

${ }^{\mathrm{a}}$ One-way analysis of variance by F-test.

${ }^{b}$ The difference in results of five group was significant if the numerical value was

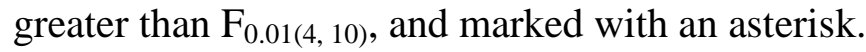

${ }^{\mathrm{c}} \mathrm{NS}$ represent not significant.

${ }^{\mathrm{d}}$ Obtained by F-value table. 

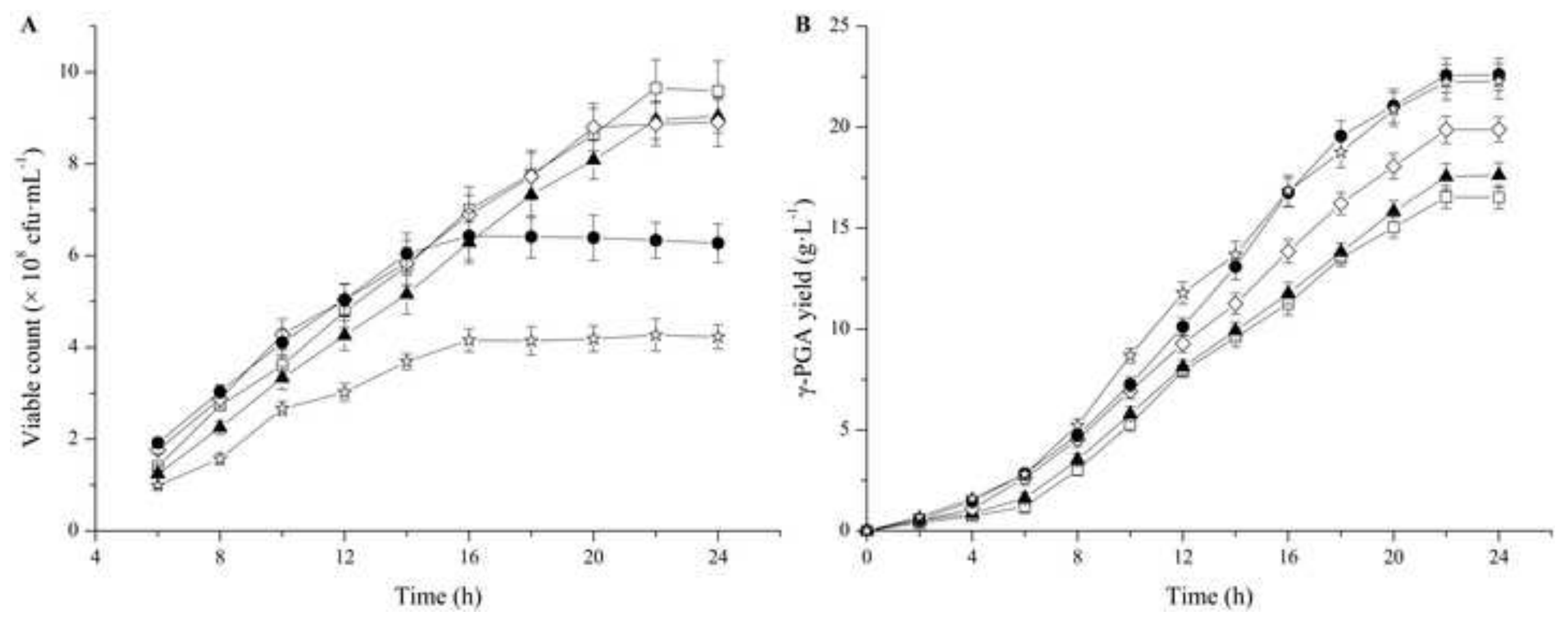

$$
\text { Time }
$$

$$
\text { ime (h) }
$$



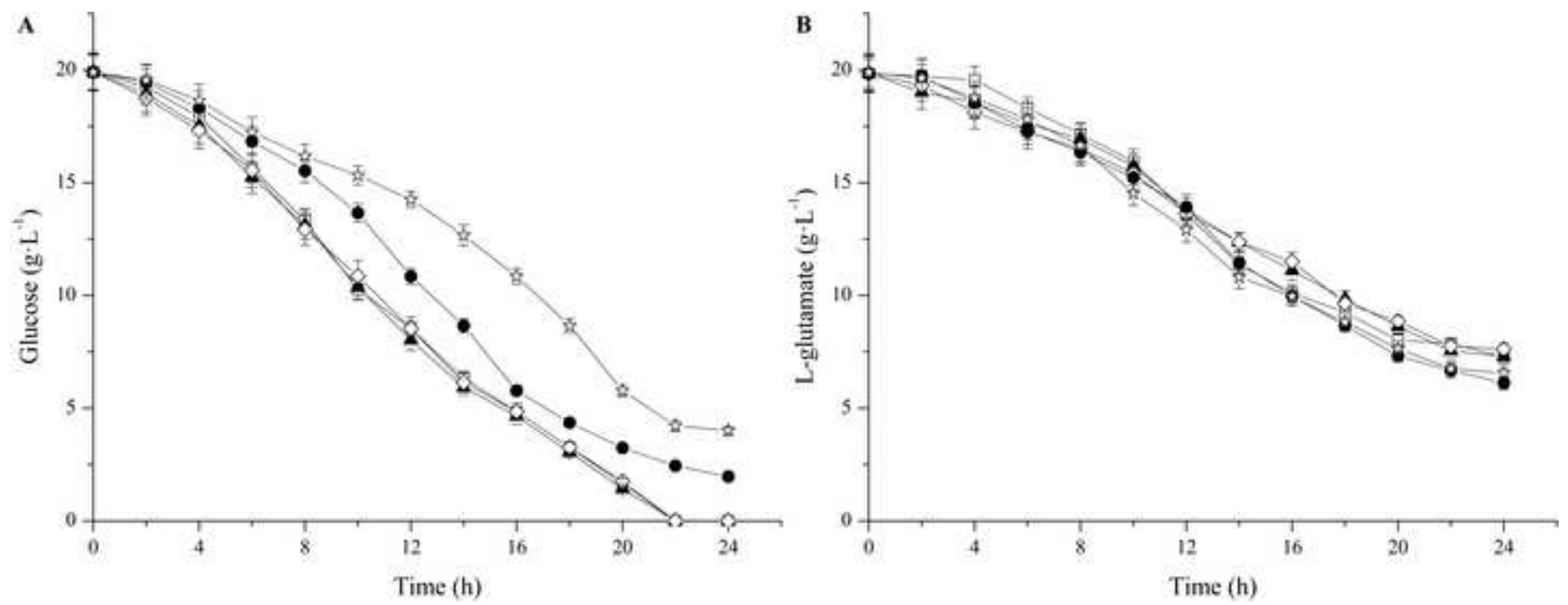


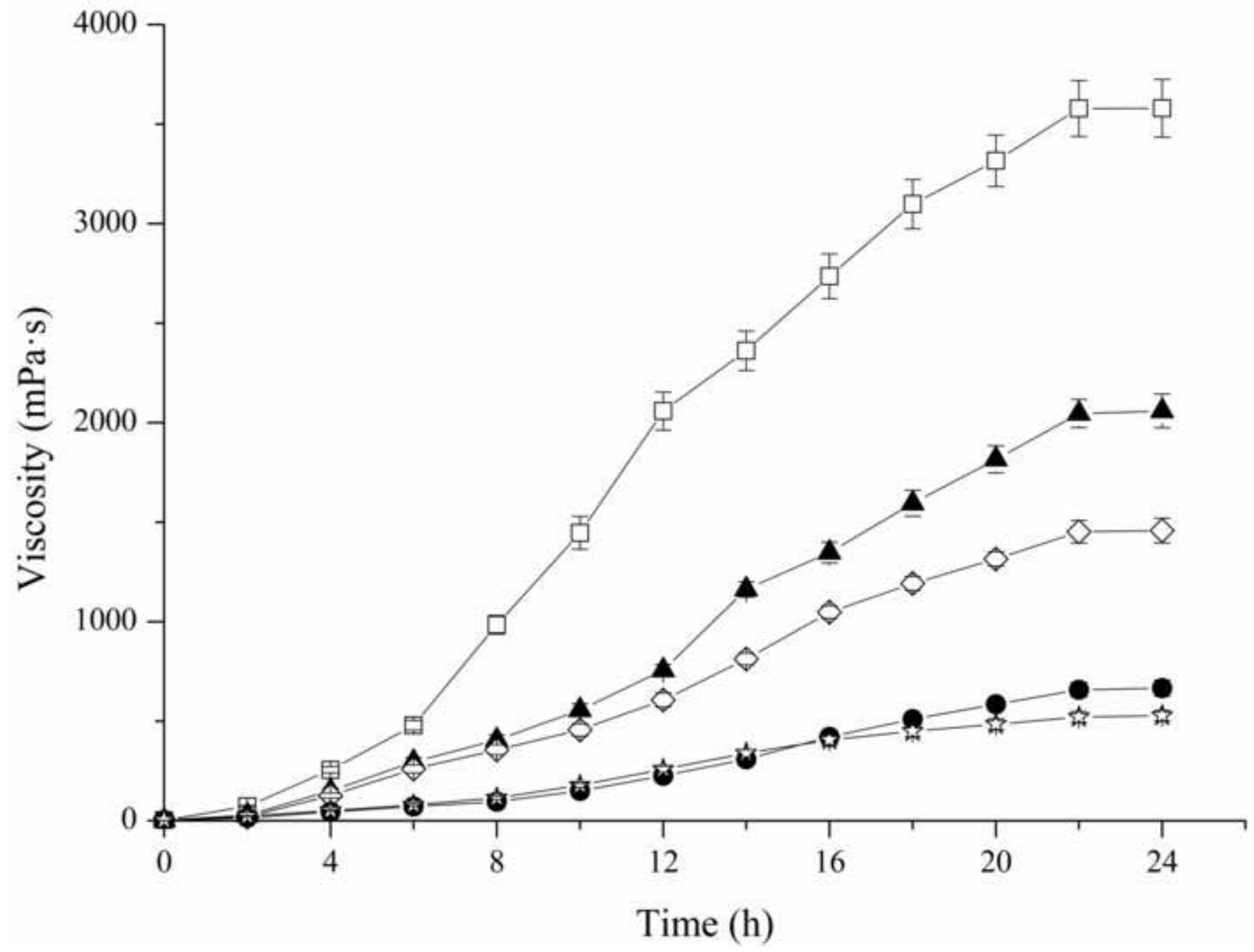



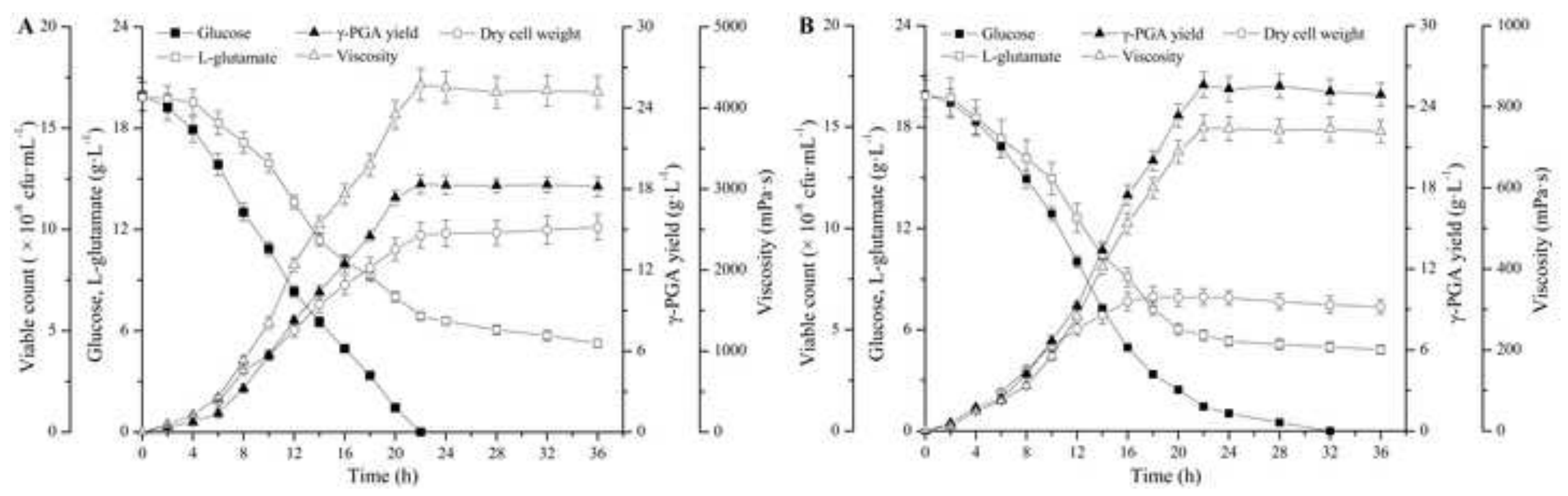
A iso-CIT $\gamma$-PGA $18.32 \mathrm{~g} \cdot \mathrm{L}^{-1}$ $\underset{5.68 \times 10^{-3}}{\mathrm{ICINH}} 64.7$

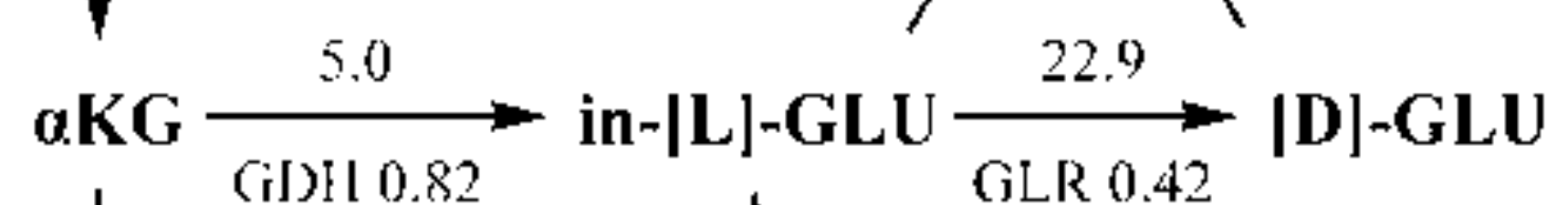

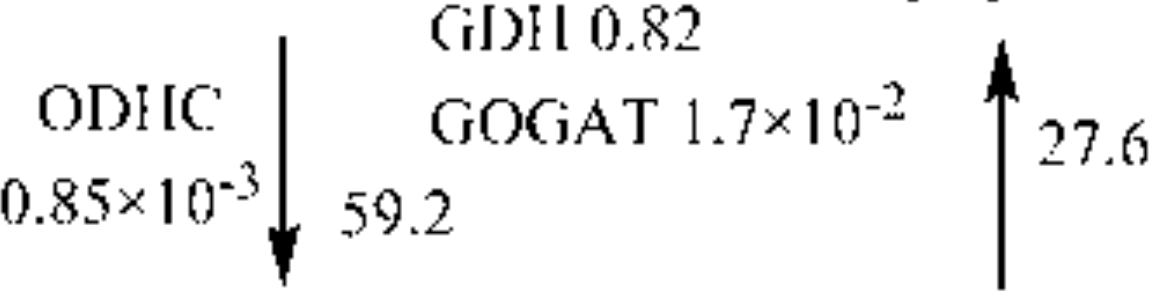

\section{SUC-CoA ex-[L]-GLU}

B iso-CIT \begin{tabular}{c|c} 
ICIH \\
$7.95 \times 10^{-3}$
\end{tabular}

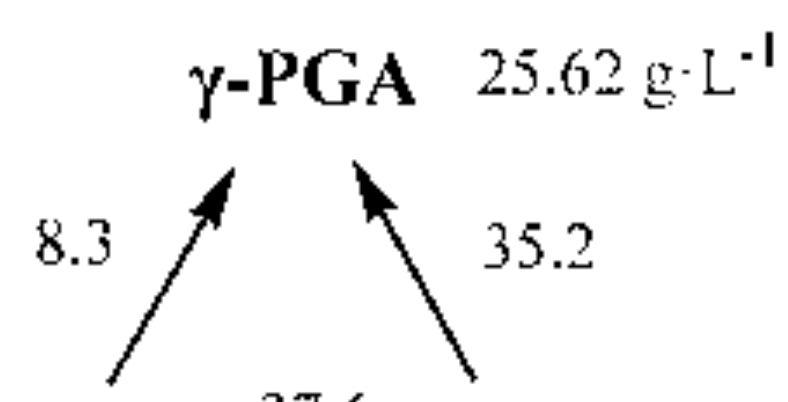

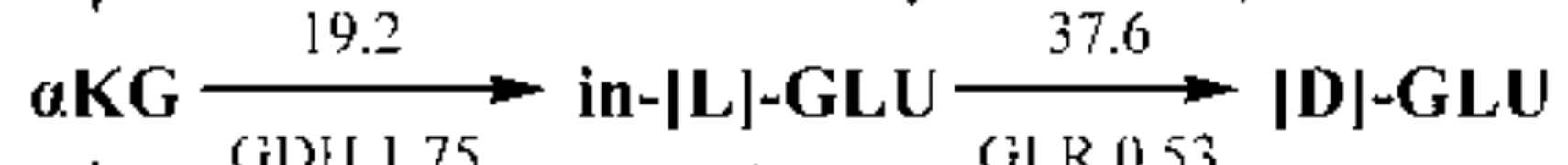

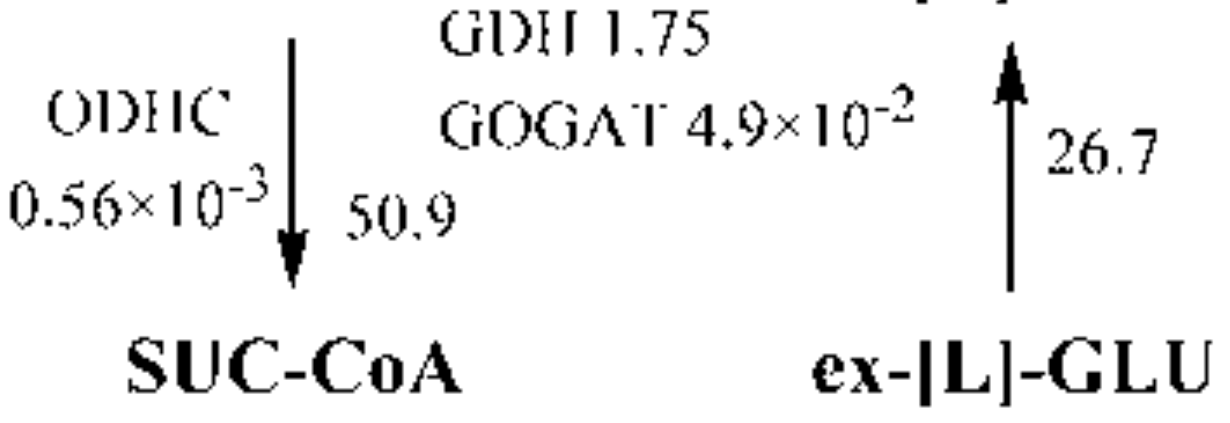




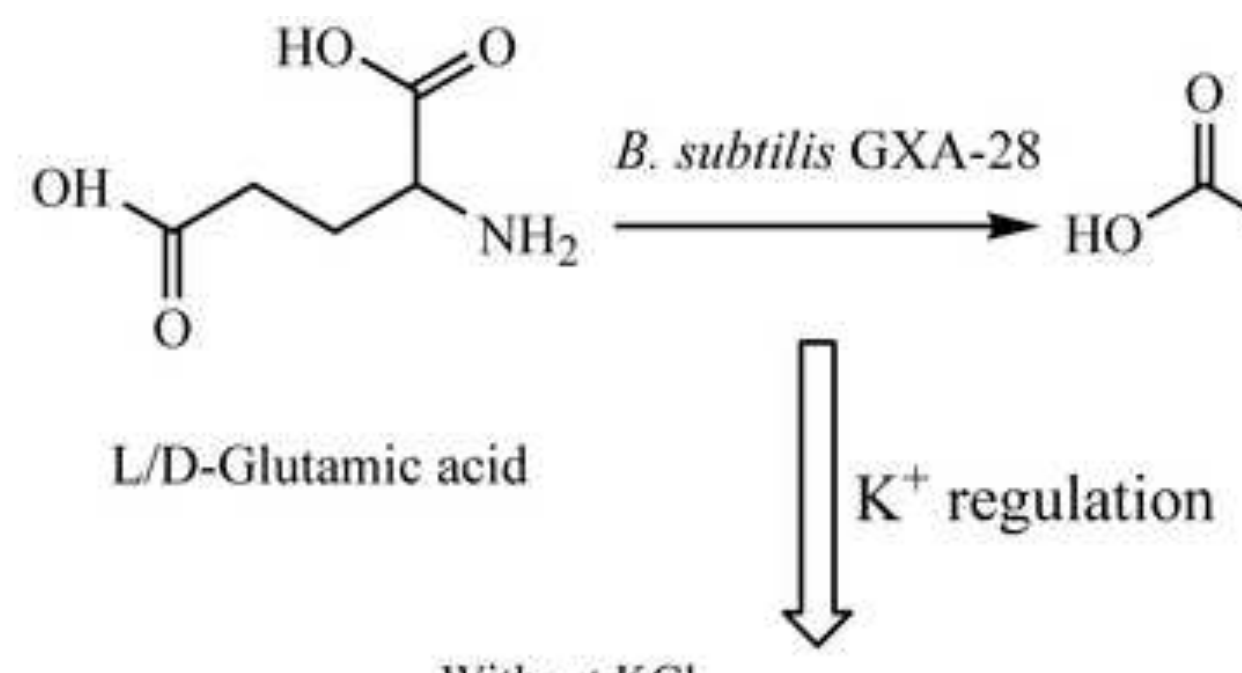

\section{Without $\mathrm{KCl}$}
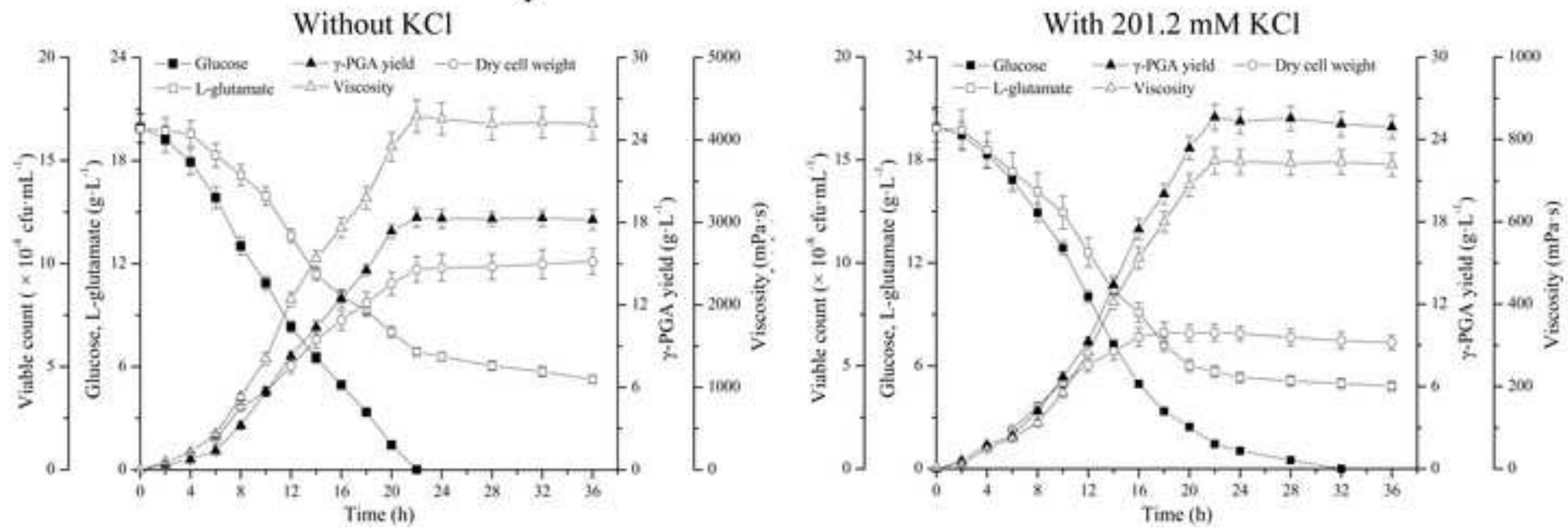